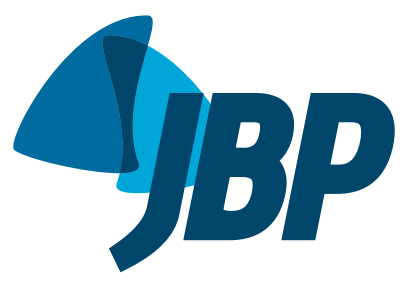

\title{
Prevalence of self-reported smoking experimentation in adolescents with asthma or allergic rhinitis
}

\author{
Silvia de Sousa Campos Fernandes' ${ }^{1}$, Cláudia Ribeiro de Andrade', \\ Alessandra Pinheiro Caminhas ${ }^{2}$, Paulo Augusto Moreira Camargos ${ }^{1}$, \\ Cássio da Cunha Ibiapina ${ }^{1}$.
}

1. Departamento de Pediatria, Faculdade de Medicina, Universidade Federal de Minas Gerais, Belo Horizonte (MG) Brasil.

2. Grupo de Pneumologia Pediátrica Faculdade de Medicina, Universidade Federal de Minas Gerais, Belo Horizonte (MG) Brasil.

Submitted: 7 November 2015. Accepted: 25 February 2016

Study carried out in the Departamento de Pediatria e no Grupo de Pneumologia Pediátrica, Faculdade de Medicina, Universidade Federal de Minas Gerais, Belo Horizonte (MG) Brasil.

\begin{abstract}
Objective: To determine the prevalence of smoking experimentation among adolescents with asthma or allergic rhinitis. Methods: This was a cross-sectional study involving adolescent students (13-14 years of age) in the city of Belo Horizonte, Brazil. The participants completed the Centers for Disease Control and Prevention and International Study of Asthma and Allergies in Childhood questionnaires, both of which have been validated for use in Brazil. We calculated the prevalence of smoking experimentation in the sample as a whole, among the students with asthma symptoms, and among the students with allergic rhinitis symptoms, as well as in subgroups according to gender and age at smoking experimentation. Results: The sample comprised 3,325 adolescent students. No statistically significant differences were found regarding gender or age. In the sample as a whole, the prevalence of smoking experimentation was $9.6 \%$. The mean age for smoking experimentation for the first time was 11.1 years of age (range, 5-14 years). Among the adolescents with asthma symptoms and among those with allergic rhinitis symptoms, the prevalence of self-reported smoking experimentation was $13.5 \%$ and $10.6 \%$, respectively. Conclusions: The proportion of adolescents with symptoms of asthma or allergic rhinitis who reported smoking experimentation is a cause for concern, because there is strong evidence that active smoking is a risk factor for the occurrence and increased severity of allergic diseases.
\end{abstract}

Keywords: Asthma/epidemiology; Rhinitis/epidemiology; Smoking/epidemiology.

\section{INTRODUCTION}

Tobacco is a legal drug that is widely used throughout the world. According to the World Health Organization, tobacco kills up to half of its users and will account for an estimated 8 million deaths annually by the year 2030; four out of five such deaths will occur in low- or middle-income countries. In addition, tobacco use is the major risk factor for noncommunicable diseases such as cancer, cardiovascular disease, diabetes, and chronic lung disease. ${ }^{(1)}$

The majority (70-80\%) of smokers take up the habit before adulthood, setting up smoking as a pediatric disease that should therefore should be included in programs of care for children and adolescents worldwide. ${ }^{(1,2)}$ This is particularly important, because the late consequences of smoking on health are directly related to the duration and intensity of the habit. ${ }^{3,4)}$

According to one study conducted in Brazil, smoking experimentation in childhood or adolescence increases the chance of smoking in adulthood by 34 times, making it a predictor of that. ${ }^{(5)}$ The National Student Health Study, ${ }^{(6)}$ conducted in 2012, involved 109,104 9th-grade students (13-15 years of age) in various regions of Brazil, including all 26 state capitals and the Federal District of Brasília.
The authors found that $19.6 \%$ of the students evaluated had already experimented with smoking

Passive and active smoking are both risk factors for asthma and allergic rhinitis in adolescents. ${ }^{(7-9)}$ There are currently few data related to the long-term consequences of active smoking in childhood and adolescence, although there is some evidence suggesting that those consequences are substantial. $(10,11)$ There have been few studies attempting to determine whether the prevalence of asthma symptoms is associated with smoking experimentation or active smoking in children and adolescents. ${ }^{(9)}$

Therefore, this study aimed to evaluate the prevalence of smoking experimentation in adolescents with symptoms of asthma or allergic rhinitis in the city of Belo Horizonte, Brazil.(12)

\section{METHODS}

In this cross-sectional study, involving adolescent students, the International Study of Asthma and Allergies in Childhood (ISAAC) questionnaire, ${ }^{(11)}$ which assesses the prevalence and severity of symptoms of asthma and allergic rhinitis, was employed.

According to the ISAAC protocol, the study population should comprise at least 3,000 students between 13 and 
14 years of age, randomly selected from at least 14 schools. The Belo Horizonte Municipal Department of Education provided a list of public schools, including the number of students per school and the school year. The drawing was made by school from a list randomly generated in the program Epi Info, version 6.04.

\section{Study criteria}

We included students from 13 to 14 years of age who were enrolled at the schools selected for the study and completed the ISAAC questionnaire. The parents or legal guardians of all participating students gave written informed consent. All other students were excluded from the study.

\section{Definitions}

We evaluated 13- and 14-year-olds because adolescents of those ages are most likely to still be attending school, resulting in a larger pool of students and facilitating data collection. The ISAAC questionnaire is a widely used tool that has been validated for use in epidemiological studies of asthma and allergic rhinitis.

To assess the prevalence of symptoms of asthma and allergic rhinitis among adolescents, we used the version of the ISAAC questionnaire that was translated to Portuguese and validated for use in Brazil by Solé et al. (13) The questions used in order to determine the prevalence of the symptoms of asthma and allergic rhinitis were, respectively, "Have you had wheezing or whistling in the chest in the past 12 months?" and "In the past 12 months, have you had a problem with sneezing, or a runny, or blocked nose when you did not have a cold or the flu?"

Students who reported having smoked at least once were classified as experimenters. ${ }^{(14)}$ To analyze the prevalence of smoking experimentation among the students, we used the questionnaire developed for the Centers for Disease Control and Prevention Global Youth Tobacco Survey. ${ }^{(15)}$ The two questions employed were "Have you ever tried or experimented with cigarette smoking, even one or two puffs?" and "How old were you when you first tried a cigarette?"

In the selected schools, the combined questionnaire was administered to all 8th- and 9th-grade students who were 13 or 14 years old. To avoid losses due to school absenteeism, we visited each school at least twice.

The questionnaire was completed by the students themselves, in the classroom, under the supervision of one of the researchers, who had been trained and instructed not to interfere with the process.

\section{Statistical analysis}

Data analysis was performed using the Statistical Package for Social Sciences, version 14.0 for Windows (SPSS Inc., Chicago, IL, USA). We calculated ratios for the prevalence of asthma symptoms, allergic rhinitis symptoms, and smoking experimentation in the general population in relation to that observed in the students who reported symptoms of asthma and those who reported symptoms of allergic rhinitis. We also calculated the proportion of students with asthma symptoms and with allergic rhinitis symptoms in relation to gender and to age at smoking experimentation.

\section{Ethical considerations}

The study was approved by the Research Ethics Committee of the Federal University of Minas Gerais and by the Belo Horizonte Municipal Department of Education. After the school board had given its authorization, we obtained written informed consent from the parents or legal guardians of all participating students.

\section{RESULTS}

The sample comprised 3,325 students, of whom $1,825(54.9 \%)$ were 13 years of age. Of the 3,325 students evaluated, 1,858 (56.1\%) were female (Table $1)$. Gender distribution did not differ between the 13-year-old and 14-year-old age groups.

In our study sample, the prevalence of asthma symptoms was $19.8 \%$. The prevalence of symptoms of allergic rhinitis was $35.3 \%$.

Smoking experimentation was reported by 310 (9.6\%) of the 3,325 students evaluated (Table 2 ). The mean age at smoking experimentation was 11.1 years (range, 5-14 years). In the sample as a whole, smoking experimentation was reported by $9.5 \%$ of the females and $9.8 \%$ of the males, a difference that was not statistically significant ( $p=0.759)$.

Of the 635 adolescents with asthma symptoms, 86 (13.5\%) reported smoking experimentation, compared with $118(10.6 \%)$ of the 1,116 with allergic rhinitis (Table 2).

\section{DISCUSSION}

This study confirmed that smoking experimentation occurs in adolescents with symptoms of asthma and allergic rhinitis in Brazil.

It is known that approximately $80 \%$ of adolescent smokers develop nicotine dependence, and smoking experimentation can thus rapidly become addiction. . $^{(16)}$ However, there have been few studies on smoking experimentation among adolescents. According to studies conducted in Brazil, the prevalence of smoking experimentation among adolescents in the country ranges from $14.6 \%$ to $47.5 \% .^{(6,17-20)}$ In the present study, using the Portuguese-language version of the ISAAC questionnaire, supplemented with questions

Table 1. Demographic characteristics of the study sample. ${ }^{a}$

\begin{tabular}{ll} 
Characteristic & $(\mathbf{N}=\mathbf{3 , 2 3 5 )}$ \\
Fender & \\
$\quad$ Male & $1,858(56.1)$ \\
Age & $1,377(43.9)$ \\
13 years & \\
14 years & $1,825(54.9)$ \\
\hline
\end{tabular}

aalues expressed as $n(\%)$. 
Table 2. Prevalence of smoking experimentation in the sample as a whole, as well as among adolescents with and without symptoms of asthma or allergic rhinitis.

\begin{tabular}{|c|c|c|c|}
\hline Population & $\begin{array}{c}\text { Total } \\
\mathbf{N}\end{array}$ & $\begin{array}{c}\text { Experimenters } \\
n(\%)\end{array}$ & $95 \% \mathrm{Cl}$ \\
\hline Sample as a whole & 3,235 & $310(9.6)$ & $(8.6-10.6)$ \\
\hline $\begin{array}{l}\text { Adolescents with } \\
\text { asthma symptoms }\end{array}$ & 635 & $86(13.5)$ & $(10.8-16.2)$ \\
\hline $\begin{array}{l}\text { Adolescents without } \\
\text { asthma symptoms }\end{array}$ & 2,560 & $224(8.7)$ & $(7.6-9.8)$ \\
\hline $\begin{array}{l}\text { Adolescents with } \\
\text { allergic rhinitis } \\
\text { symptoms }\end{array}$ & 1,116 & $118(10.6)$ & $(8.8-12.4)$ \\
\hline $\begin{array}{l}\text { Adolescents without } \\
\text { allergic rhinitis } \\
\text { symptoms }\end{array}$ & 2,028 & $187(9.2)$ & $(7.9-10.5)$ \\
\hline
\end{tabular}

focused on smoking experimentation selected from the Global Youth Tobacco Survey questionnaire, ${ }^{(15)}$ which has also been validated for use in Brazil, ${ }^{(20)}$ we found a lower rate $(9.6 \%)$ in our sample as a whole.

A recent study conducted in Brazil showed that the overall prevalence of smoking experimentation among 9th-grade students (adolescents from 13 to 15 years of age) was $19.6 \%$, being highest $(28.6 \%)$ in the south of the country and lowest (14.9\%) in the northeast. ${ }^{(6)}$ That same study also showed that the proportion of 15-year-olds who had tried their first cigarette at $\leq$ 13 years of age was $15.4 \%$. ${ }^{(6)}$ The only previous study conducted in the city of Belo Horizonte was a homebased study focusing on smoking among adolescents and young adults (individuals 15 to 24 years of age), in which the overall prevalence of smoking and smoking experimentation was found to be $11.7 \%$ and $51.0 \%$, respectively. ${ }^{(21)}$ That represents the highest reported prevalence of smoking experimentation among all of the studies analyzed, although the age of the study sample differed from that of ours.

In the literature, there is considerable variation among the reported rates smoking experimentation, and the rates found in the present study were lower than those previously reported. There are several possible explanations for that discrepancy. Because our study was not population-based, it is possible that the number of adolescents who had tried smoking was underestimated. To minimize that bias (i.e., avoid losses due to school absenteeism), the questionnaire was applied in two visits. It is also possible that some of the adolescents evaluated denied having tried smoking for fear of exposure or due to shyness, characteristics typical of adolescents in relation to risk behavior, despite having been assured, at the time of completing the questionnaire, that the data would be kept confidential.
In general, there is great variability across studies in relation to smoking, because there are various definitions of smoking status: sporadic smoking, occasional smoking, habitual smoking, current smoking, and daily smoking. There have been few studies dealing with smoking experimentation. Therefore, there is need for more research in order to minimize these variations through the use of standardized methodology, which could facilitate the diagnosis and improve the monitoring of smoking among adolescents.

The focus of the present study was to analyze the prevalence of smoking experimentation among adolescents with asthma and allergic rhinitis. We found no studies were found on this subject in the literature, which is worrisome because there is strong evidence that active smoking is a risk factor for asthma, rhinoconjunctivitis, and atopic dermatitis, as well as for greater severity of their symptoms. ${ }^{(22)}$

The results of the present study could prove useful because, in addition to being in agreement with the literature regarding the early onset of smoking experimentation, they also show that the prevalence of such experimentation was higher among adolescents with symptoms of asthma or allergic rhinitis, especially those with asthma, than among adolescents in the general population.

The design of the present study did not allow us to identify the possible causes of the difference between adolescents with asthma or allergic rhinitis and adolescents in the general population in terms of the prevalence of smoking experimentation, especially between adolescents with and without asthma. However, although smoking by parents is a known risk factor for smoking and respiratory diseases in their offspring ${ }_{r}^{(23,24)}$ adolescence is a risk phase, mainly influencing the behavior of patients with chronic diseases, which can result in higher smoking prevalence, underscoring the need to maintain and intensify smoking control measures in this age group, especially in adolescents with allergic respiratory diseases.

In conclusion, reducing the prevalence of smoking is considered one of the greatest challenges for public health, (25) and public policies have been developed in order to reduce smoking and nicotine dependence, as well as passive smoking, among children and adolescents. (26) Despite the implementation of various educational, legislative, and economic interventions to combat smoking in Brazil, adolescents in the country are still vulnerable to smoking experimentation and smoking-related diseases. Health professionals should pay special attention to the possibility of smoking among adolescents, especially among those with asthma or allergic rhinitis.

\section{REFERENCES}

1. World Health Organization (WHO) [homepage on the Internet] Geneva: WHO; c2016 [cited 2016 Mar 21]. Ban tobacco advertising to protect young people; [about 4 screens]. Available from: http://www. who.int/mediacentre/news/releases/2013/who_ban_tobacco/en

2. Farber HJ, Walley SC, Groner JA, Nelson KE; Section on Tobacco

Control. Clinical Practice Policy to Protect Children From Tobacco, Nicotine, and Tobacco Smoke. Pediatrics. 2015;136(5):1008-17. http://dx.doi.org/10.1542/peds.2015-3108

3. World Health Organization (WHO) [homepage on the Internet] Geneva: WHO; c2016 [cited 2016 Mar 21]. Inequalities in young 
people's health. Health behaviour in school-aged children. International report from the 2005/2006 survey. [Adobe Acrobat document, 208p.]. Available from: http://www.euro.who.int/_data/ assets/pdf_file/0005/53852/E91416.pdf?ua=1

4. Malcon MC, Menezes AM, Chatkin M. Prevalence and risk factors for smoking among adolescents [Article in Portuguese]. Rev Saude Publica. 2003;37(1):1-7. http://dx.doi.org/10.1590/S003489102003000100003

5. Silva MA, Rivera IR, Carvalho AC, Guerra Ade H Jr, Moreira TC. The prevalence of and variables associated with smoking in children and adolescents. J Pediatr (Rio J). 2006;82(5):365-70.

6. Instituto Brasileiro de Geografia e Estatística (IBGE) [homepage on the Internet].Brasília: IBGE [cited 2016 Mar 21]. Pesquisa Nacional de Saúde do Escolar 2012 [about 1 screen]. Available from: http://www. ibge.gov.br/home/estatistica/populacao/pense/2012/

7. Gómez M, Vollmer WM, Caceres ME, Jossen R, Baena-Cagnani CE. Adolescent smokers are at greater risk for current asthma and rhinitis. Int J Tuberc Lung Dis. 2009;13(8):1023-8.

8. Mak KK, Ho RC, Day JR. The associations of asthma symptoms with active and passive smoking in Hong Kong adolescents. Respir Care. 2012;57(9):1398-404. http://dx.doi.org/10.4187/respcare.01548

9. Yoo S, Kim HB, Lee SY, Kim BS, Kim JH, Yu J, et al. Effect of active smoking on asthma symptoms, pulmonary function, and BHR in adolescents. Pediatr Pulmonol. 2009;44(10):954-61. http://dx.doi. org/10.1002/ppul.21066

10. Barreto SM, Giatti L, Casado L, de Moura L, Crespo C, Malta D. Contextual factors associated with smoking among Brazilian adolescents. J Epidemiol Community Health. 2012;66(8):723-9. http://dx.doi.org/10.1136/jech.2010.122549

11. Henderson AJ. The effects of tobacco smoke exposure on respiratory health in school-aged children. Paediatr Respir Rev. 2008;9(1):21-7. http://dx.doi.org/10.1016/j.prrv.2007.11.005

12. Asher MI, Keil U, Anderson HR, Beasley R, Crane J, Martinez F, et al. International Study of Asthma and Allergies in Childhood (ISAAC): rationale and methods. Eur Respir J. 1995;8(3):483-91. http://dx.doi. org/10.1183/09031936.95.08030483

13. Solé D, Vanna AT, Yamada E, Rizzo MC, Naspitz CK. International Study of Asthma and Allergies in Childhood (ISAAC) written questionnaire: validation of the asthma component among Brazilian children. J Investig Allergol Clin Immunol. 1998;8(6):376-82.

14. Centers for Disease Control and Prevention (CDC) [homepage on the Internet]. Atlanta: CDC; 2013 [cited 2013 Sep 23]. Global Youth Tobacco Survey (GYTS) -- Overview. Available from: http://nccd.cdc. gov/gtssdata/Ancillary/Documentation.aspx?SUID=1\&DOCT=1

15. Centers for Disease Control and Prevention (CDC). [homepage on the Internet]. Atlanta: CDC; c2013 [cited 2013 Sep 23]. National
Youth Tobacco Survey (NYTS) [about 4 screens]. Available from http://www.cdc.gov/tobacco/data_statistics/surveys/nyts/index.htm

16. Lenney W, Enderby B. "Blowing in the wind": a review of teenage smoking. Arch Dis Child. 2008;93(1):72-5. http://dx.doi.org/10.1136/ adc.2006.109702

17. Bordin R, Nipper VB, Silva JO, Bortolomiol L. Smoking prevalence among students from a metropolitan area in the southern region of Brazil, 1991 [Article in Portuguese]. Cad Saude Publica 1993:9(2):1859. http://dx.doi.org/10.1590/S0102-311X1993000200010

18. Machado Neto AS, Cruz AA. Smoking among school adolescents in Salvador (BA)[Article in Portuguese]. J Pneumol. 2003;29(5):264-72. http://dx.doi.org/10.1590/S0102-35862003000500004

19. Pasqualotto AC, Pasqualotto GC, Santos RP, Segat FM, Guillande $S$, Benvegnú LA. Relationship between adolescence and tobacco: a study of students sociodemographic factors in Santa Maria, RS, Brazil [Article in Portuguese]. Pediatria (São Paulo). 2002;24:11-6.

20. de Almeida LM, Cavalcante TM, Casado L, Fernandes EM, Warren CW, Peruga A, et al. Linking Global Youth Tobacco Survey (GYTS) data to the WHO Framework Convention on Tobacco Control (FCTC): the case for Brazil. Prev Med. 2008;47 Suppl 1:S4-10. http://dx.doi. org/10.1016/j.ypmed.2007.11.017

21. Abreu MN, Souza CF, Caiaffa WT. Smoking among adolescents and young adults in Belo Horizonte, Minas Gerais State, Brazil: the influence of family setting and social group. Cad Saude Publica. 2011:27(5):935-43. http://dx.doi.org/10.1590/S0102 $311 \times 2011000500011$

22. Annesi-Maesano I, Oryszczyn MP, Raherison C, Kopferschmitt C, Pauli G, Taytard A, et al. Increased prevalence of asthma and allied diseases among active adolescent tobacco smokers after controlling for passive smoking exposure. A cause for concern? Clin Exp Allergy. 2004;34(7):1017-23. http://dx.doi.org/10.1111/j.13652222.2004.02002.x

23. Landau LI. Parental smoking: asthma and wheezing illnesses in infants and children. Paediatr Respir Rev. 2001;2(3):202-6. http:// dx.doi.org/10.1053/prrv.2001.0141

24. Tanaka K, Miyake Y, Arakawa M, Sasaki S, Ohya Y. Prevalence of asthma and wheeze in relation to passive smoking in Japanese children. Ann Epidemiol. 2007;17(12):1004-10. http://dx.doi. org/10.1016/J.annepidem.2007.07.108

25. Doll R. Tobacco: an overview of health effects. In: Zaridze D, Peto $R$, editors. Tobacco: a major international health hazard. Lyon: International Agency for Research on Cancer; 1986. p. 11-22.

26. Farber HJ, Nelson KE, Groner JA, Walley SC: Section on Tobacco Control. Public Policy to Protect Children From Tobacco, Nicotine and Tobacco Smoke. Pediatrics. 2015;136(5):998-1007. http://dx.doi org/10.1542/peds.2015-3109 